\title{
MEMBERIKAN PUJIAN YANG TEPAT MENURUT GROWTH MINDSET
}

\author{
NI LUH PUTU DIAN SAWITRI \\ Universitas Mahasaraswati Denpasar \\ niluhputudiansawitri@gmail.com
}

\begin{abstract}
The most important yet trivial things that leads to our kids' success is the choice of words that we use to praise them. Sound trifling indeed, however this has a great impact to how our children later perceive the world. Thanks to Professor Carol Dweck who has done many researches about what is actually behind a child success and failure. The answer goes to mindset, where Dweck categorized mindset into two; fixed and growth mindset. A simple concept but it does take huge amount of our time and effort as parents, educator to teach our kids to be a responsible, open to challenge individuals, and able to learn from mistakes and always perform the best of them.
\end{abstract}

\section{Pendahuluan}

Bagaimanakah cara memuji anak yang tepat? Tidakkah nantinya anak akan bergantung pada pujian? Atau anak akan kecewa ketika apa yang dilakukannya tidak mendapat pujian?

Sejak dahulu penghargaan dan hukuman pernah menjadi tren dalam dunia pendidikan. Hal ini merupakan pengaruh dari Behaviorism dengan tokohnya yang terkenal Ivan Pavlov dan BF Skinner. Anak diberi penghargaan untuk hal-hal baik yang mereka lakukan dan mereka akan dihukum untuk setiap perbuatan buruk yang mereka lakukan. Terkadang terdapat pergeseran dimana ketika anak melakukan hal-hal baik dianggap sebagai hal yang wajar dan ketika berbuat salah maka akan dihukum.

Penghargaan yang diberikan bisa bermacam-macam, mulai dari pujian yang bersifat verbal maupun tindakan lainnya yang bersifat non verbal. Demikian pula halnya dengan hukuman ada yang verbal dan non verbal. Akan tetapi pemberian hukuman pada anak didik yang berkaitan dengan fisik sang anak kini mulai ditinggalkan dengan adanya undangundang perlindungan anak. Masih tersisa di ingatan kita tentang bagaimana beberapa guru harus merasakan dinginnya jeruji besi hanya karena menghukum anak didiknya.

Pada dasarnya pujian dan hukuman adalah salah satu cara untuk menekankan perbuatan yang baik dan mengeleminasi perbuatan buruk yang dilakukan sang anak, dengan harapan anak akan tetap melakukan perbuatan yang dianggap baik dan meninggalkan perbuatan yang dianggap buruk. Lalu sudahkah kita memberi penghargaan dengan tepat? Apakah benar penghargaan yang kita berikan mendukung mereka untuk tetap melakukan kebaikan?

Dalam artikel kali ini akan membahas tentang hasil penelitian Dr. Carol Dweck yang berkaitan tentang pemberian penguatan atau pujian yang berujung pada pembentukan mind set pada anak. Untuk memahami urgensi tentang pentingnya pemberian penguatan/pujian yang tepat, maka sebelumnya akan dipaparkan ilustrasi yang merupakan pengalaman langsung penulis dengan anaknya sendiri yang berumur 4 tahun.

\section{Ilustrasi}

Dika, seorang anak yang berumur 4 tahun 3 bulan, mengikuti pendidikan usia dini semenjak 2 tahun terakhir. Gurunya sering memberi hadiah sticker bagi mereka yang 
telah melakukan hal yang baik dan benar. Kompetisi kadang dipilih untuk membuat kegiatan menjadi lebih menarik. Mereka yang menjadi juaranya mendapat penghargaan mulai dari tepuk tangan, pujian sampai hadiah.

Hampir semua anak suka ketika mendapat penghargaan, perhatian lebih, apalagi hadiah. Ternyata, dirumahpun Dika menikmati kompetisi. Mulai dari sekedar siapa yang lebih cepat, siapa yang lebih dulu habis, dan siapa yang lebih kuat. Menikmati tepuk tangan dan perhatian lebih dari orang tua ketika ia berhasil melakukan hal baik.

Namun sayangnya, karena keinginannya untuk menjadi juara, sang anak mulai menghalalkan segala cara utuk memenangkan kompetisi. Ketika ia menentukan sendiri kompetisi minum susu, maka dengan sengaja ia meminta ibunya untuk menuangkan air sedikit saja agar nantinya ia bias menghabiskan susu lebih cepat. Ia pun tak segan meminta lawannya untuk sengaja memperlabat diri agar ia bias menjadi juara.

Melihat ilustrasi diatas, sepertinya nilai dalam kompetisi yang kurang menjadi jiwanya. Wajar karena ia masih anak-anak. Akan tetapi tanpa pemahaman yang kuat maka semua kompetisi itu akan menjadi tidak sehat. Selalu menang tidak lah tepat, yang lebih tepat adalah bagaimana bias kembali lebih baik lagi setelah kekalahan atau kegagalan. Memberikan penghargaan yang tepat dengan cara yang benar menjadi solusi untuk menciptakan mindset yang berkembang.

\section{Mindset menurut Carol Dweck}

Dweck dan koleganya selama lebih dari 30 tahun telah melakukan penelitian untuk menemukan benang merah antara mindset dan hasil belajar siswa. Beberapa siswa dianggap mampu melakukan lebih baik ketika menemui kegagalan sementara beberapa siswa lain terlihat sangat sedih bahkan untuk kesalahan yang kecil.

Perbedaan mendasar yang ada dalam diri mereka adalah mindset/pola pikir. Mereka yang percaya bahwa keteguhan usaha akan memberikan hasil yang baik menunjukkan pencapaian memuaskan, sementara mereka yang terlanjur menanamkan dalam diri mereka bahwa mereka tidak mampu maka akan menunjukkan hasil yang tidak memuaskan.

"A mindset is a belief about oneself and one's basic qualities" (Walters, 2015)

Mindset dapat diartikan sebagai kepercayaan terhadap diri dan kualitas diri. Dweck sendiri membagi jenis mindset/pola pikir menjadi dua yang disebut Growth mindset dan Fixed mindset. Growth mindset mengacu pada pola pikir bertumbuh yang meyakini semua pencapaian akan mudah terwujud dengan usaha keras. Sementara Fixed mindset mengacu pada pola pikir yang menganggap bahwa keberhasilan, kepintaran, kesuksesan merupakan sesuatu yang sudah ada dalam diri seseorang dan bukan atas usaha.

Lebih jauh dalam website Mindset Works dijelaskan bahwa guru-guru memegang peranan yang amat besar dalam membangun pola pikir anak didik. Melalui pemberian penguatan dalam bentuk pujian, guru mampu menciptakan kondisi dimana siswa merasa termotivasi ataupun malah berbalik dan lebih memilih jalan keluar yang mudah.

“...a person's true potential is unknown (and unknowable); that it's impossible to foresee what can be accomplished with years of passion, toil, and training." (Dweck, 2000)

Dalam kutipan diatas jelas diartikan bahwa potensi seseorang tidak diketahui secara pasti dan tidak mungkin untuk diprediksi 
apa yang mungkin akan dicapai dengan kesungguhan, latihan dan kerja keras.

Kepintaran bukanlah layaknya batu yang dipahat sehingga menjadi bentuk tertentu, melainkan kepintaran merupakan sesuatu yang bertumbuh dan akan terus berkembang sesuai dengan lingkungan dan dukungan yang diberikan. Kepintaran juga bukanlah sesuatu yang tetap dan statis. Kepintaran, dan keberhasilan merupakan sesuatu yang dapat berubah dan sangat mungkin dicapai melalui kerja keras. Hal inilah yang dipercayai oleh Dweck dalam mengembangkan penelitiannya tentang motivasi.

\section{Perbedaan Growth mindset dan Fixed mindset}

Berikut akan dijelaskan perbedaan mendasar antara Growth Minset dan Fixed mindset diambil dari http://www.laurelschool.org/

\begin{tabular}{|c|c|c|}
\hline & Fixed mindset & Growth mindset \\
\hline Prestasi & $\begin{array}{l}\text { Berarti membuktikan bahwa } \\
\text { anda pintar }\end{array}$ & $\begin{array}{l}\text { Berarti bahwa anda belajar dan } \\
\text { sedang berkembang }\end{array}$ \\
\hline Pintar & $\begin{array}{l}\text { Berarti anda tidak membuat } \\
\text { kesalahan }\end{array}$ & $\begin{array}{l}\text { Berarti bahwa anda berhasil } \\
\text { menaklukkan tantangan dan } \\
\text { membuat kemajuan }\end{array}$ \\
\hline Kesalahan & $\begin{array}{l}\text { Mengarah pada kehilangan } \\
\text { rasa percaya diri }\end{array}$ & $\begin{array}{l}\text { Menandai area yang perlu } \\
\text { dikembangkan }\end{array}$ \\
\hline Kegagalan & Mengacu pada rasa malu & $\begin{array}{l}\text { Berarti } \text { anda belum } \\
\text { sepenuhnya } \\
\text { potensi }\end{array}$ \\
\hline Usaha & $\begin{array}{l}\text { Tidak diperlukan selama kita } \\
\text { pintar dan selalu beralasan } \\
\text { ketika mengalami kegagalan }\end{array}$ & $\begin{array}{l}\text { Adalah jalan yang harus } \\
\text { dilalui untuk membuat kita } \\
\text { lebih baik }\end{array}$ \\
\hline Kesuksesan & $\begin{array}{l}\text { Didefinisikan sebagai } \\
\text { menjadi yang terbaik dan itu } \\
\text { terjadi karna talenta }\end{array}$ & $\begin{array}{l}\text { Didefinisikan sebagai } \\
\text { melakukan usaha untuk } \\
\text { menjadi terbaik dan ini terjadi } \\
\text { berdasarkan motivasi }\end{array}$ \\
\hline Nilai yang bu & $\begin{array}{l}\text { Menandakan ini waktunya } \\
\text { untuk menyarah }\end{array}$ & $\begin{array}{l}\text { Menandakan ini waktunya } \\
\text { untuk bekerja lebih keras lagi }\end{array}$ \\
\hline Umpan balik & $\begin{array}{l}\text { Terasa mengancam karena } \\
\text { akan menunjukkan kebaikan } \\
\text { atau keburukan dari usaha } \\
\text { sebelumnya }\end{array}$ & $\begin{array}{l}\text { Sangat diterima karena } \\
\text { membantu menunjukkan area } \\
\text { atau bidang yang perlu } \\
\text { ditingkatkan }\end{array}$ \\
\hline Meminta & $\begin{array}{l}\text { Menunjukkan kekurangan } \\
\text { atau kelemahan yang } \\
\text { seharusnya tidak ditunjukkan }\end{array}$ & $\begin{array}{l}\text { Adalah strategy yang sangat } \\
\text { berguna demi berkembangan }\end{array}$ \\
\hline Ancaman ster & $\begin{array}{l}\text { Sangat tinggi karena merasa } \\
\text { takut mendapatkan stereotype } \\
\text { negative }\end{array}$ & $\begin{array}{l}\text { Sangat rendah, karena merasa } \\
\text { bahwa stereotype merupakan } \\
\text { pandangan orang yang kurang } \\
\text { akurat }\end{array}$ \\
\hline Teman yang beı & $\begin{array}{l}\text { Merupakan dasar untuk } \\
\text { merasa terancam dan iri }\end{array}$ & Merupakan sumber inspirasi \\
\hline
\end{tabular}

Sangat jelas nampak dalam ciri-ciri orang dengan fixed mindset bahwa mereka akan merasa sangat buruk ketika melakukan kesalahan dan berusaha menghindari 
tantangan yang diluar kemampuannya karena rasa takut akan kegagalan dan stereotype. Ketika mendapatkan penilaian buruk, maka orang dengan fixed mindset akan segera menyerah dan memutuskan bahwa hal itu bukanlah bidangnya dan tidak akan mencobanya untuk kedua kali. Disamping itu, fixed mindset berusaha mencari alasan atas kesalahan atau kegagalan yang dihadapi.

Sementara ciri-ciri orang dengan growth mindset selalu memandang positive tiap kesalahan ataupun kegagalan yang dihadapi sebagai jalan untuk memperbaiki kualitas diri. Growth mindset sangat terbuka terhadap kritik dan saran, dan menganggap teman-temannya yang berprestasi sebagai sumber inspirasi.

Yang menjadi pertanyaan sekarang adalah, pola pikirmanakah yang dimiliki anak-anak didik kita sekarang? Apakah mereka mudah menyerah terhadap suatu tantangan? Ataukah mereka mudah merasa iri dengan keberhasilan orang lain? Apakah mereka melimpahkan kesalahan pada hal lain ketiga mengalami kegagalan? Apakah ranking dalam kelas menjadi satu-satunya tolak ukur kepintaran mereka di dalam kelas?

Pertanyaan berikutnya yang tidak kalah penting adalah, siapakah yang membentuk pola pikir mereka tersebut? Bisakah pola pikir yang sudah terlanjur keliru diubah kembali ke growth mindset?

Jawabannya tentu BISA!

\section{Growth mindset dan Pujian}

Menumbuhkan growth mindset dalam diri anak didik tentunya memerlukan dukungan lingkungan. Dockterman dan Blackwell (2014) menyatakan bahwa : "core beliefs, content-specific skills, and classroom culture are also essential to success". "...However, mindset is not entirely an individual matter. It is continually influenced by peers, teachers, parents, and the wider culture"
http://ejournal.ihdn.ac.id/index.php/AW Growth mindset tentunya tidak muncul sendiri begitu saja, perlu arahan, asahan, dan dorongan dari lingkungan sekitar yang tidak lain adalah orang tua dan guru sebagai pendidik di sekolah. Penelitian pioneer yang dilakuakn Dweck dan rekannya Mueller membuktikan bahwa hal-hal kecil seperti pujian dapat dengan mudah merubah persepsi anak terhadap sesuatu. Kata-kata pujian tertentu ternyata mengarahkan siswa pada fixed mindset, sementara kata-kata pujian lain mengarahkan siswa pada growth mindset.

Dweck dan Mueller melakukan penelitian terhadap sekelompok siswa sekolah dasar yang kemudian diberikan perlakuan berbeda dalam dalam hal pujian. Awalnya siswa diberikan beberapa masalah untuk diselesaikan. Setelah itu kelompok pertama dipuji atas kepintarannya dengan mengatakan kata sejenis "Bagus, kamu pintar" atau "Kamu sangat pandai". Sementara kelompok kedua diberikan pujian atas usaha mereka dengan kata sejenis "Bagus, kamu sudah berusaha dengan sangat baik" atau "Kerja kerasmu luar biasa". Berikutnya, kedua kelompok siswa tersebut diberikan kembali soal namun kali ini soal yang diberikan dengan tingkat kesulitan yang jauh untuk level mereka. Walaupun kedua kelompok mengalami kegagalan, namun kelompok pertama mencoba menyelesaikan lebih sedikit soal dari sebelumnya, sedangkan kelompok kedua menunjukkan usaha yang lebih keras dengan mencoba menyelesaikan lebih banyak soal. Berikutnya kembali kedua kelompok siswa tadi diberikan kesempatan untuk menyelesaikan soal dengan level yang sama persis dengan percobaan pertama. Ternyata hasilnya sangat mengejutkan, dimana kelompok siswa yang dipuji atas kepintarannya menunjukkan penurunan pencapaian sementara siswa yang dipuji atas kerja kerasnya menunjukkan peningkatan.

Those praised for effort overwhelmingly chose to try something harder, and their performance improved following a failure (Mueller and Dweck, 1998). 
Diluar dugaan, siswa yang dipuji atas usahanya menunjukkan keinginan untuk mencoba sesuatu yang lebih sulit dan
http://ejournal.ihdn.ac.id/index.php/AW akhirnya menunjukkan peningkatan bahkan setelah mengalami kegagalan.

\section{Impact of Praise on Resilience After Failure}

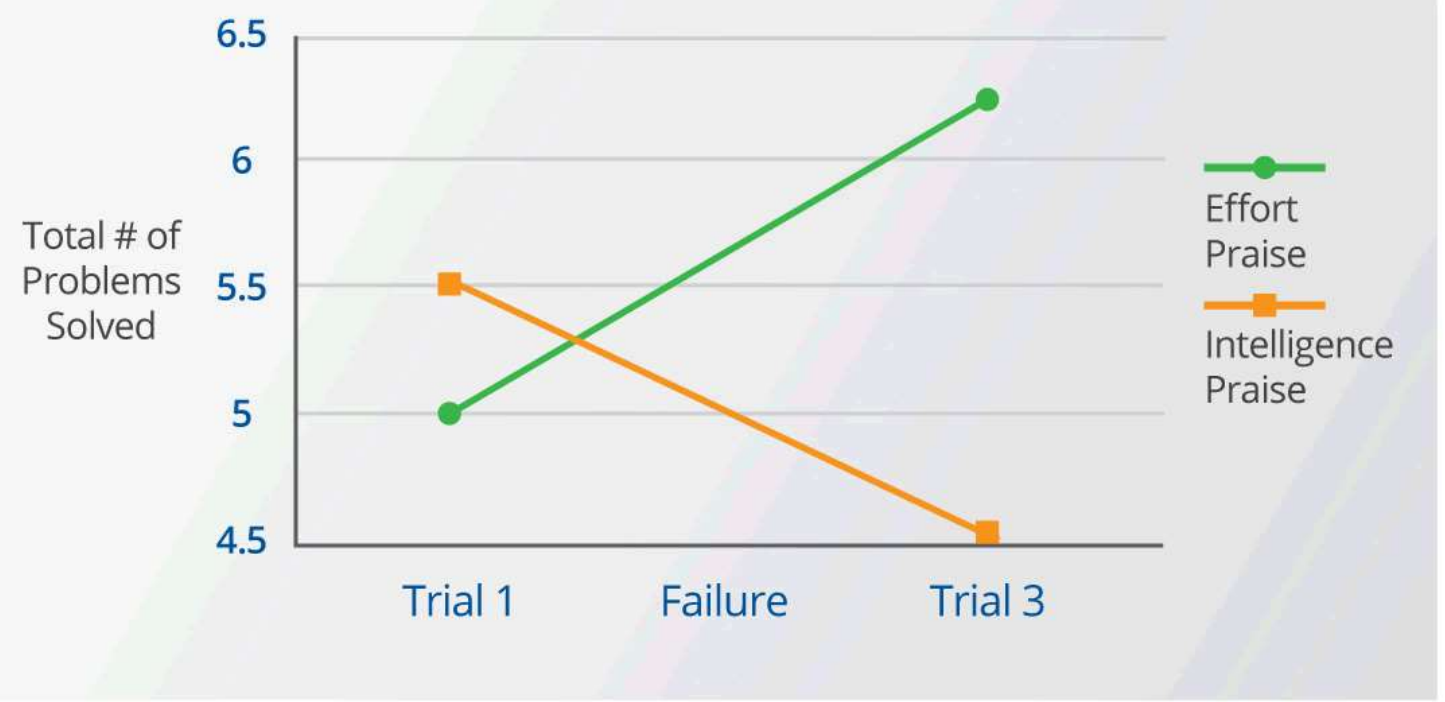

Gambar diambil dari www.mindsetworks.com

Dengan memuji kepintarannya maka kita secara tidak langsung melabeli anak dengan kualitas tersebut. Sehingga anak cenderung untuk menjaga label itu dan orang tetap memujinya pintar. Yang terjadi adalah mereka mereasa tidak termotivasi ketika menemui kesulitan yang diluar kemampuannya, dan cenderung menunjukkan penurunan karena terpengaruh stereotype yang terlanjur dibangun atas dirinya.

Penelitian lain oleh Blackwell et.al (2007) yang mencoba mengajarkan tentang growth mindset kepada siswa kelas 7 dalam pembelajaran matematika. Kelompok pertama diberikan informasi tentang apa itu growth mindset dan bagaimana otak mampu berkembang, sementara kelompok kedua hanya diberikan informasi umum tentang otak manusia. Kedua kelompok siswa ini diajarkan matematika dengan strategi belajar yang sama. Namun hasilnya, siswa yang mendapat pemahaman dengan growth mindset ternyata menunjukkan hasil belajar yang lebih tinggi dibandingkan dengan siswa yang tidak mendapat informasi tentang growth mindset.

The study strategies alone weren't enough to improve their performance. Students need to know how to get better, AND they need to believe that exercising those skills will pay off. (Dockterman and Blackwell, 2014)

Strategy pembelajaran saja tidaklah cukup untuk meningkatkan kemampuan siswa. Mereka perlu tahu bagaimana caranya untuk menjadi lebih baik dan mereka harus percaya bahwa tetap melatih kemampuan yang mereka miliki nantinya akan menunjukkan hasilnya.

Hasil penelitian tersebut menunjukkan betapa besarnya pengaruh pemahaman tentang growth mindset terhadap prestasi anak. 


\section{Impact of a Growth Mindset Intervention}

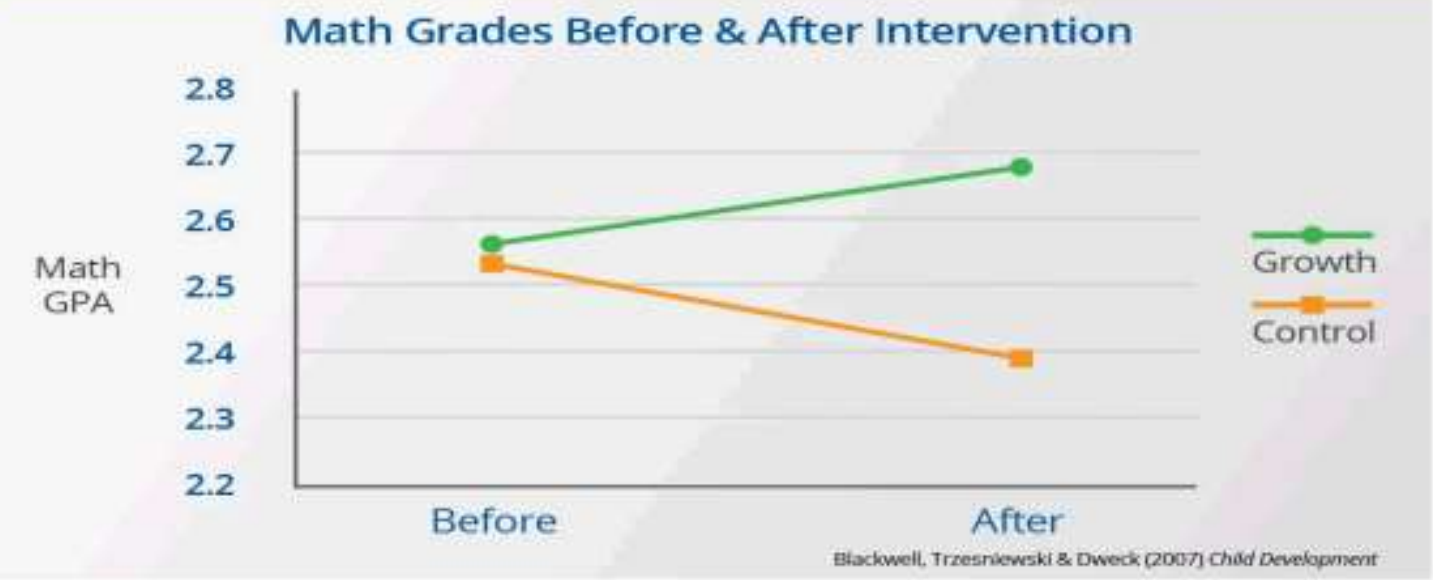

Gambar diambil dari www.mindsetworks.com

Lalu apakah hanya siswa yang perlu memahami tentang growth mindse ini? Tentu saja tidak. Kita selaku pendidik juga perlu memahami betul bagaimana menciptakan budaya yang akan mendukung growth mindset ini di dalam kelas. Sebuah studi kasus di sekolah dasar Fiske di Amerika dimana guru-gurunya diberikan pemahaman tentang growth mindset menunjukkan hasil prestasi belajar siswa yang jauh diats rata-rata sekolah dasar di
Amerika.

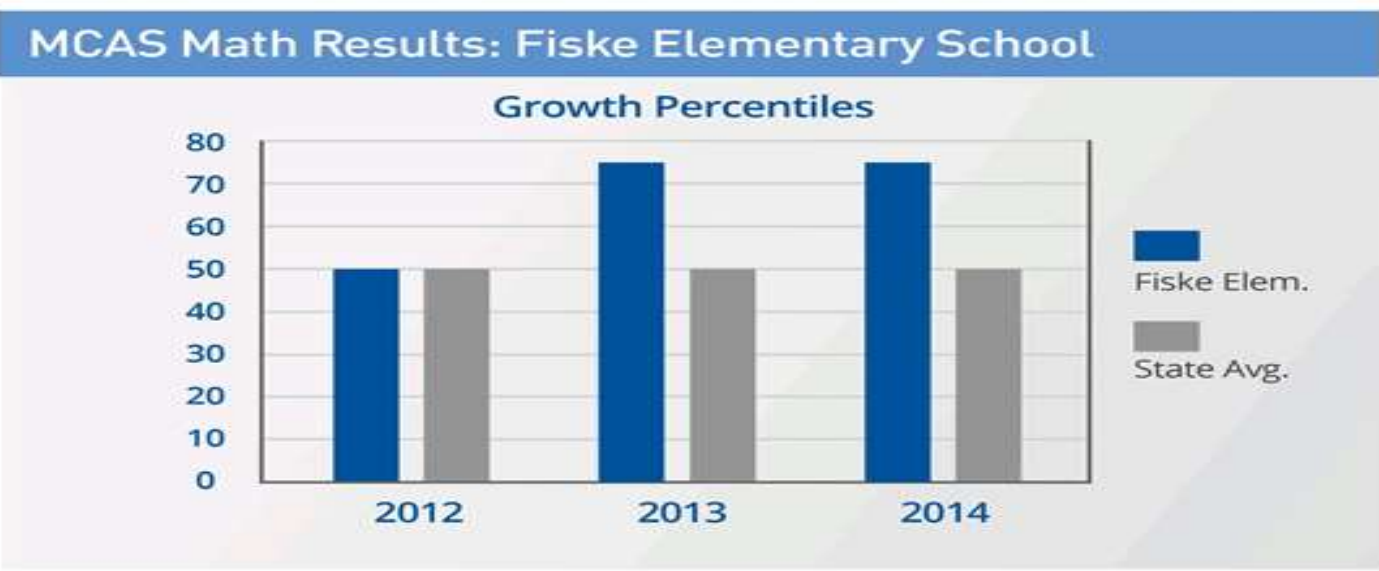

Gambar diambil dari www.mindsetworks.com

Guru-guru di Sekolah dasar Fiske ikut serta dalam program mindset book dan menyelesaikan program pengembangan diri melalui test online MindsetMaker ${ }^{\mathrm{TM}} \mathrm{di}$ tahun kedua. Hasil belajar matematika siswa di sekolah dasar Fiske memiliki kesamaan jika dibandingkan dengan hasil belajar keseluruhan siswa sekolah dasar di Amerika. Namum peningkatan yang signifikan ditunjukkan di tahun berikutnya. Hal ini terjadi karena perubahan budaya dalam kelas akibat penerapan growth mindset. 
Mengapa hal ini menjadi sangat penting? Tentu saja karena guru merupakan inti dari sebuah kelas. Bagaimana interaksi dalam kelas itu terjadi, bagaimana seorang guru menciptakan suasana belajar yang kondusif semua bergantung pada guru itu sendiri.

Steuer et.al (2013) menunjukkan hal-hal yang dapat menciptakan apa yang mereka sebut "error climate" bagaimana guru dan teman sebaya bereaksi ketika seorang siswa membuat kesalahan. Hal ini sangat berpengaruh terhadap terciptanya lingkungan dengan growth mindset yang akan mendukung siswa untuk berani menerima tantangan ataupun sebaliknya menghindar dari tantangan.

Jika kita ingin mengembangkan kultur growth mindset maka kita memerlukan dukungan dari manjemen kelas, sekolah dan budaya lingkungan sekitar untuk ikut berpartisipasi menumbuhkan dan memelihara growth mindset ini. Karena jika tidak usaha dari satu pihak saja mungkin tidak akan menunjukkan hasil yang maksimal dan berkelanjutan.

Teaching a growth mindset, using appropriate praise, providing examples of how genius is the result of hard work, having students write about how their learning connects to their lives, and other techniques have all shown promise in getting students to believe that they can succeed. Without that belief, students have no reason to try. (Docketrman and Blackwell, 2014)

Mengajarkan tentang growth mindset melalui penggunaan pujian yang tepat merupakan contoh bagaimana suksesnya hasil dari kerja keras itu. Mengarahkan siswa untuk tahu bagaimana proses belajar mereka berhubungan langsung dengan kehidupan mereka mereka pun harus percaya bahwa mereka bias berhasil. Tanpa pemahaman itu, maka siswa tidak memiliki alasan untuk tetatp mencoba.

Apa yang Guru Bisa Lakukan?
http://ejournal.ihdn.ac.id/index.php/AW Dweck dan Blackwell mengajukan beberapa langkah praktis untuk menumbuhkan growth mindset dalam kelas, adapun langkah-langkahnya sebagai berikut:

1. Set ekspektasi yang tinggi (bukan sekedar standar). Beri tantangan pada siswa sehingga siswa tahu bahwa mereka memiliki kemampuan untuk mencapai ekspektasi itu.

2. Ciptkan lingkungan yang toleran terhadap resiko. Sediakan lingkungan yang menghargai tantangan, pembelajaran, dan usaha diatas kesempurnaan

3. Ketika memberikan umpan balik, focus pada proses-sesuatu yang bisa dikontrol oleh siswa bukan kemampuan personalnya. Hindari memuji anak akan kepintarannya melainkan focus dalam menjelaskan pentingnya usaha yang dia lakukan untuk mencapai kesuksesan.

4. Perkenalakan pada siswa bahwa otak kita itu bisa mengembang. Tunjukkan pada siswa bahwa otak kita berkembang lewat usaha dan belajar.

Lebih jauh, Walter (2015) menunjukan bahwa guru dapat menetapkan taktik antara lain:

1. Ajarkan siswa tentang growth mindset vs fixed mindset lewat selfassessment dan diskusi

2. Hindari penggunaan label (seperti "pintar" dan "bodoh") yang mengindikasikan bhawa intelegensi adalah kemampuan yang tetap.

3. Berikan pujian atas usaha, startegi dan progress (perkembangan), bukan kepintaran atau kemampuan.

4. Berikan mereka kesempatan untuk sebuah tantangan, dan sampaikan pada mereka bahwa aktivitas yang menantang itu menyenangkan, dan 
kesalahan membantu mereka untuk belajar dan berkembang.

Maureen Boylan dalam artikel yang ditulis Geiser (2010) memberikan beberapa saran dalam memberikan pujian bagi anak. Beberapa yang harus dilakukan antara lain:

- Buat kontak secara fisik. Sentuh dengan lembut si anak misalnya pada bahu, atau berikan pelukan, ciuman atau 'toss' ketika anda mengekspresikan persetujuan anda. Acungan jempol ataupun senyuman dapat memberikan efek yang sama. Bahasa tubuh yang positif dapat berarti lebih dari sekedar kata-kata yang anda katakana terhadap anak-anak.

- Sampaikan dengan tulus. Orang tua yang bermaksud baik mungkin akan secara tidak sengaja seringkali mengucapkan "Kerja Bagus" dalam satu hari tanpa menyadarinya. Anak anda dapat mengetahui apakah anda mengatakannya dengan tulus atau tidak. Spesifiklah tentang apa yang anda suka dan yakinlah dengan nada suara anda. Tatap mata anak anda dan senyum dengan tulus untuk menunjukkan betapa anda merasa bahagia.

- Berikan pujian yang mengacu pada persona anak. Terkadang orang tua menghargai pencapaian yang didapatkan oleh anak dengan menggunakan ukuran dirinya sendiri. Sehingga pujian yang di lontarkan menjadi "Saya pikir itu cukup bagus" yang sebenarnya mengacu pada standar orang tua bukan standar anak. Untuk itu, pujilah usaha kemampuan anak dalam menuntaskan sesuatu. Cobalah dengan mengatakan "Kamu mengerjakan tugas bersihbersih dengan sangat baik" atau "kamu sudah berusaha dengan keras menyelesaikan gambar itu!" buatlah pujian itu untuk anakmu
http://ejournal.ihdn.ac.id/index.php/AW bukan tentang apa yang anda rasakan atau pikirkan.

Jangan lakukan hal berikut dalam memberikan pujian pada anak:

- Jangan memuji secara berlebihan. Terlalu banyak pujian bias berakibat buruk. Jika anda memujinya untuk segala hal maka ia akan mengharapkannya setiap saat ia melakukan sesuatu. Berikan pujian ketika pertama kali ia menaruh sepatunya dengan baik di rak, tetapi tidak setiap kali ia melakukannya. Ketika kita memberika pujian secara berlebihan, maka pujian itu sendiri akan kehilangan keefektifannya.

- Jangan berikan pujian terhadp karakternya. Pastikan pujian diberikan terhadap perilaku atau tindakan, dan bukan komentar tentang karakter anak. Ketika anda mengatakan "kamu baik" atau "kamu buruk", maka ini akan menjadi cerminan karakter anak, dan ia mungkin akan beranggapan bahwa hal ini tidak dapat dirubah. Lebih baik mengatakan "apa yang kamu lakukan itu baik" atau "apa yang kamu lakukan itu buruk" hal ini akan menjadikan sesuatu yang menjadi pilihan bagi si anak untuk merubahnya.

- Jangan membuat pujian menjadi kritikan. Pastikan anda tidak mencampur pujian dengan kritikan. Sebagai contoh, ketika anak anda mencoba berpakaian sendiri dan anda memujinya "bagus kamu berpakaian sendiri, tapi bajunya sangat tidak cocok". Dengan demikian pujiannya akan menjadi sia-sia. Orang tua mungkin berpikir untuk memperbaiki setiap kesalahan yang dibuat anak-anak, namun sesungguhnya hal itu lebih membawa dampak buruk karna hal tersebut menandakan bahwa anak 
anda tidak cukup baik. Akan lebih baik jika hanya focus pada keberhasilannya berpakaian tanpa bantuan siapapun.

Untuk itulah guru dan orang tua perlu menaruh perhatian lebih terhadap pemberian pujian terhadap anak. Berikan perhatian pada prosesnya, berikan penghargaan pada usahanya, berikan pujian atas perbuatan baik yang mereka lakukan.

\section{Simpulan}

Walaupun terkesan remeh, pujian sungguh memberikan dampak yang sangat besar bagi perkembangan mental anak didik. Jika kita menginnginkan anak kita tumbuh dan berkembang dengan growth mindeset dan menjadi pribadi yang terbuka terhadap tantangan serta bertumbuh dalam setiap kesalahan, maka mulailah memberikan perhatian terhadap pilihan kata-kata yang kita gunakan untuk memuji mereka.

Kunci perubahan ada di tangan kita para orangtua dan tenaga pendidik. Berilah pujian dengan tulus, selalu puji usahanya bukan hasil akhirnya, ukurkan keberhasilan itu pada diri anak dan bukan dengan ukuran kita orang dewasa. Anak didik kita mampu mencapai apapun asalkan ada dorongan dan dukungan yang tepat. Tidak ada lagi label "bodoh" dan "pintar" namun yang ada adalah merka yang "berusaha keras" dan "belum berusaha dengan keras".

\section{References}

Blackwell, L., Trzesniewski, K., \& Dweck, C.S. 2007. Implicit theories of intelligence predict achievement across an adolescent transition: A longitudinal study and an intervention. Child Development, 78. 246263.
http://ejournal.ihdn.ac.id/index.php/AW Dockterman, David. Blackwell, Lisa. 2014. Growth Mindseet in Context Content and Culture Matter Too. International Center for Leadership Education.

Dweck, Carol S. 2010. Boosting Achievement with Messages that Motivate. Education Canada Vol.47 (2). Canadian Education Association

Dweck, Carol S. 2012. Mindset: How You Can Fulfil Your Potential. New York. Constable Book.

Dweck, C. 2006. Mindset: The New Psychology of Success. New York: Random House

Geiser, Traci. 2010. Praising Your Toddlers: Do's and Don'ts. Retrieved from https://www.education.com/magazine/artic le/praising-toddler-donts/ on $10^{\text {th }}$ February 2016

Mueller, C. \& Dweck, C. 1998. Praise for intelligence can undermine children>s motivation and performance. Journal of Personality and Social Psychology, 75 (1), 33-52.

Steuer, G., Rosentritt-Brunn, G., \& Dresel, M. 2013. Dealing with errors in mathematics classrooms: Structure and relevance of perceived error climate. Contemporary Educational Psychology, 38 196-210

Walters, Samantha. 2015. Growth mindset: A Literature Review. TEMESCAL Assosiate.

http://www.laurelschool.org/

http://www.mindsetwork.com 